\title{
Decision-making preferences and information needs among Greek breast cancer patients
}

\author{
Augoustina Almyroudi', Lesley F. Degner², Vassiliki Paika', Nicholaos Pavlidis ${ }^{3}$ and Thomas Hyphantis ${ }^{\text {** }}$ \\ 'Department of Psychiatry, Medical School, University of loannina, Greece \\ ${ }^{2}$ Faculty of Nursing, University of Manitoba, Winnipeg, MB, Canada \\ ${ }^{3}$ Department of Medical Oncology, Medical School, University of loannina, loannina, Greece
}

* Correspondence to: Department of Psychiatry, Medical School, University of loannina, loannina 45110 , Greece. E-mail: tyfantis@cc.uoi.gr
Received: 27 January 2010

Revised: 23 May 2010

Accepted: 31 May 2010

\begin{abstract}
Objectives: We aimed at assessing Greek breast cancer patients' preferences for participation in treatment decision making and their information needs.

Methods: In a cross-sectional study, 329 breast cancer patients were administered at the Control Preferences Scale, a card-sort measurement designed to elicit preferences for participation in decision making. Information needs were assessed with Cassileth's Information Styles Questionnaire.

Results: The majority of patients $\mathbf{( 7 1 . 1 \% )}$ preferred to play a passive role in treatment decision making, with most of them wanting to delegate responsibility of the decision completely to their doctor $(\mathbf{4 5 . 3 \%})$. A collaborative role was preferred by $24 \%$, whereas only 4.6\% chose an active role. Most women expressed a general desire for as much information as possible about their illness $(62.6 \%)$, but a substantial proportion $(37.4 \%)$ did not want detailed information; instead, they wished to avoid awareness of bad news. Women who desired less informational details and preferred a passive role requested less frequently a mammography $(\boldsymbol{p}<0.001)$ and/or Pap test $(\boldsymbol{p}<\mathbf{0 . 0 0 0 5})$ prediagnostically.

Conclusions: This study's findings showed that the proportion of patients who wanted to play a passive role in decision making is the highest reported compared to similar studies from other countries, indicating the impact of the dominating paternalistic model of the doctor-patient relationship in the Greek medical encounter. The association of desired information details and decision-making preferences with screening for cancer procedures prediagnostically highlights the significance of providing the patients with the appropriate information and the choices available for their treatment. Copyright (C) 2010 John Wiley \& Sons, Ltd.
\end{abstract}

Keywords: breast cancer; decision making; information; oncology; patient participation; role preference; treatment decisions

\section{Introduction}

In recent years, there has been much debate over the patient's participation in medical decision making, and an increasing emphasis has been given on patient's autonomy. Patients' roles in the decision-making process range from playing an active role, i.e. patients decide themselves about treatment, through a sharing role, to a passive role in which they delegate responsibility of the decision to their physicians $[1,2]$. Although the traditional paternalistic approach has been extensively challenged $[3,4]$, shared decision making is increasingly advocated as an ideal model of physician-patient interaction [3-7]. In shared decision making, providers and patients exchange information, both express treatment preferences and after joint deliberation they may reach a mutually accepted decision [5,7]. Although it is still not clearly understood what role patients really want to play in decision making, seeking information and being involved in decision making are thought to contribute to coping processes, which in turn promote the adjustment to the disease [8], at a time when patients experience significant levels of psychological distress [9-11].

Breast cancer is considered an appropriate type of cancer for studying decision-making processes, because its treatment involves difficult choices between medically justified treatment alternatives [12]. For example, it is well established that both mastectomy and breast conserving surgery with radiation offer equivalent survival rates in early stages of breast cancer $[13,14]$. Women offered a choice of surgical treatment were shown to have better psychological well-being [15-18] and quality of life [19]. Participation in treatment decisions, though, presupposes that the patient has been 
provided with accurate information about the treatment options, their potential benefits, and side effects. However, many patients complain that clinicians do not provide an adequate amount of information [20], while others may not fully understand the information given [21].

Patients' preferences for participation in treatment decisions differ in various countries and are influenced by cultural, legal, religious, economic, and other factors. In a Canadian study, $44 \%$ of breast cancer patients preferred to share decisions with their physicians [22]. Shared decision making was also preferred by $64 \%$ of patients in a US study [23]. Although studies from European countries reported lower rates of active and shared decision preferences, still only a small minority $(10-17.3 \%)$ wanted to delegate full responsibility for the decision to doctors [24,25]. Unfortunately, however, patients often fail to achieve their preferred level of involvement $[20,24,26]$, as doctors underestimate patients' preference for participating in treatment decision making [26].

In Greece, the estimated age-standardized incidence and mortality rates per 100.000 for female breast cancer are 61.9 and 22.3, respectively [27]. The consumerist model of health care, however, is not extensively developed and paternalism is not yet challenged. Although in recent years the choice of treatment is discussed with some patients depending on their educational level and health status, physicians often decide on their own regarding the most appropriate treatment to be implemented, without previously having informed the patient in detail about the illness and the available treatment options. Despite also the fact that some consumer advocacy groups for breast cancer were recently established, they have no impact on governmental policies. In addition, there is no national screening program for breast cancer [28]. Debate on health-care reform in contemporary Greece is focused on primary care enhancement and health promotion, including encouragement of voluntary breast screening [29]. However, Greek general practitioners report that heavy workloads and lack of time make it difficult for them to engage in prevention and health promotion activities [30].

In this context, we assumed that decision-making preferences and information needs among Greek women with breast cancer might be different from those reported in other countries. Given that no previous studies examined this issue in Greece, we aimed to assess information needs and decision-making preferences among Greek women with breast cancer.

\section{Methods}

\section{Participants}

The study design was cross-sectional. The sample comprised 329 women with a confirmed diagnosis of breast cancer attending consecutively the oncological outpatient department of the University General Hospital of Ioannina, Greece, from February 2008 to September 2009. This department provides secondary and tertiary care for a general population of 400,000 . Since we aimed to assess patients' decision-making preferences in general, i.e. independently of whether their views refer to surgical treatment, adjuvant treatment or both, all patients attending the outpatient clinic during this period were invited to participate in the study, independent of the stage of the disease trajectory. Exclusion criteria were inability to read and write Greek, history of psychotic illness, alcohol and/or drug abuse or dementia, and brain metastases. Out of 420 invited patients, 364 were eligible and 329 agreed to participate (response rate $=90.4 \%$ ). Among eligible patients, no statistical significant differences in major demographic characteristics were found between the participant and the nonparticipant groups. All the procedures followed were in accordance with the ethical standards on human experimentation (World Medical Association Helsinki Declaration) and were approved by the hospital's responsible ethical committee (No 11/7.11.2006).

\section{Measures}

The data collection was via a semistructured interview performed by the same interviewer. To elicit women's preferences about the degree of control they wanted in treatment decision making, we used the Control Preferences Scale [31], which was used in previous studies in Canada [22], Sweden [24], and United Kingdom [25]. It consists of five cards (A, B, C, D, and E). Each one represents a potential role of the patient in relation to her/his physician when a decision about treatment is made. Each role is described by a statement and is illustrated by a cartoon, which helps patients of lower literacy levels to grasp the notion of patient participation. The roles range from the patient being the primary decision maker (A), through shared decision making $(\mathrm{C})$, to the patient being the passive recipient of the physician's decisions (E).

The Control Preferences Scale was translated from English into Greek using the back-translation method. The instrument was translated by a native Greek-speaking doctor, who was familiar with the literature regarding the decision-making preferences of oncological patients. The translated statements were then discussed by a bilingual expert panel consisting of a psychiatrist, a psychologist, and a nurse, to obtain conceptual rather literal equivalents of the five statements into Greek. This procedure resulted in four translated options, which were then back-translated into English by an independent native English-speaking translator, 
who had no previous knowledge of the tool. The most conceptually relevant to the original version translation was eventually chosen for testing in a group of 10 women with breast cancer and their comments were discussed in focus groups.

The cards were presented in pairs and the order of presentation was fixed. Women were asked to choose between the two cards the one that was closer to the role they preferred to play in the decision-making context. Women were not asked to state a preference for a specific decision, but to consider the role they would prefer to play in a hypothetical scenario of a consultation with their oncologist where a decision about (any) treatment must be made. This method was chosen because paternalism is not yet extensively challenged in Greece and the physician decides alone the treatment plan. Many women, therefore, might not even know about patient participation, and this hypothetical scenario, apart from capturing general views about decision making, could help the patient grasp the notion of patient participation.

Subsequently, a ranking order was produced, representing the degree of control each participant wanted to have over decision making. For example, ABCDE represents the preference order of a person that strongly desires to maintain control in decision making, whereas EDCBA represents the patient who wants to delegate responsibility for her treatment completely to her doctor. The first card in each ranking order represents the patient's most preferred role.

To establish perceived decisional role of women diagnosed with stage I or II of the disease and who had undergone primary surgery, we asked whether they had understood that they had a choice between mastectomy and breast conserving surgery when the decision was made (yes/no). This question was asked after the presentation of the Control Preferences Scale.

Information needs were assessed by Cassileth's Information Styles Questionnaire [32], which assesses patient's general and specific information preferences. It consists of three parts. Part one measures the amount of information details desired by patients on a five-point likert scale. Part two assesses the desire for specific types of information concerning disease, treatment options, and psychosocial needs, on a three-point Likert scale. In part three, patients are asked to choose a statement that best describes their general attitude toward information regarding their illness. The Cassileth's Information Styles Questionnaire was translated from English into Greek using similar methodology applied for the Control Preferences Scale.

\section{Statistical analysis}

Individual preference orders were analyzed using Coomb's 'unfolding theory' [33]. Preference orders were unfolded to determine whether they were consistent with the existence of a dominant underlying psychological dimension ranging from complete control, through sharing control to giving away control (ABCDE-EDCBA dimension). There were 120 preference orders derived from all the possible combinations of the five cards. However, only 11 were consistent with the hypothesized psychological dimension. Coombs [33] stated that at least $50 \%$ plus 1 of the preference orders would need to fall on to the dimension for establishing validity of patients' systematic preferences.

The first card selected by each woman was used to indicate her most preferred role. As only one woman had chosen card A as her preferred role, women were divided into four groups according to their most desired role: active $(\mathrm{A}+\mathrm{B})$, collaborative (C), passive collaborative (D), and passive role (E).

All the subsequent statistical analyses were performed using the Statistical Package for the Social Sciences (SPSS) 15.0 (SPSS Inc., Chicago, IL, USA) for Windows. Univariate comparisons were first conducted to assess the relationship of all independent variables with decision-making preferences and with the amount of detailed information desired. Pearson's or Spearman's correlations, two-tailed $t$-tests or one-way ANOVAs, were carried out, as appropriate [34]. Following this, two multiple regression analyses were carried out with dependent variables the decision-making preferences and the amount of information details desired. Independent variables were the statistically significant variables derived from previous univariate analyses. Collinearity between independent variables was tested based on variance inflation factors and tolerances for individual variables [35].

\section{Results}

\section{Patient's demographic and clinical characteristics}

Patients' demographic profiles and disease parameters are presented in Tables 1 and 2. Median age was 60 years with a mean of 59.5 (SD, 10.9) years. Mean disease duration was 43.37 (SD, 53.7) months. The majority had stage II disease at the time of diagnosis $(53.5 \%)$ and was treated with mastectomy (69.9\%). Most women had never done a mammography $(72.0 \%)$ on a screening basis before they were diagnosed with breast cancer.

\section{Information needs}

Most women expressed a desire for as much information as possible, either good or bad $(62.6 \%)$. An additional $15.2 \%$ wanted information only if it was 'good news'. Finally, nearly one fifth $(22.2 \%)$ wanted only to know the information they needed to care for themselves properly and wished to avoid knowledge of additional details. 
Table I. Patients' demographic characteristics

\begin{tabular}{lr}
\hline Variables & $\mathbf{N}(\%)$ \\
\hline Age & \\
$\quad<50$ years & $63(19.1 \%)$ \\
$50-69$ years & $201(61.1 \%)$ \\
$\geqslant 70$ years & $65(19.8 \%)$ \\
Education & \\
$\quad$ Primary school & $208(63.2 \%)$ \\
High school & $73(22.2 \%)$ \\
College/university & $47(14.3 \%)$ \\
Marital Status & \\
Married & $253(76.9 \%)$ \\
Single & $14(4.3 \%)$ \\
Widowed/divorced/separated & $62(18.8 \%)$ \\
Employment status & \\
Housewife & $92(28.0 \%)$ \\
Full time & $95(28.9 \%)$ \\
Retired & $142(43.2 \%)$ \\
Residence & \\
Town $\leqslant 10000$ & $133(40.4 \%)$ \\
Town $\geqslant 10000$ & $196(59.6 \%)$ \\
Relatives with cancer & $181(55.0 \%)$ \\
Relatives with breast cancer & $82(24.9 \%)$ \\
\hline
\end{tabular}

Table 2. Patients' clinical characteristics

\begin{tabular}{lc}
\hline Variables & $\mathbf{N}(\%)$ \\
\hline Time since diagnosis & \\
$0-6$ months & $107(32.5 \%)$ \\
$7-12$ months & $15(4.6 \%)$ \\
I3-24 months & $42(12.8 \%)$ \\
$\geqslant 25$ months & $165(50.2 \%)$ \\
Surgery & \\
Modified radical mastectomy & $230(69.9 \%)$ \\
Breast conserving treatment & $81(24.6 \%)$ \\
No surgery & $18(5.5 \%)$ \\
Stage of cancer (at diagnosis) & \\
I & $53(16.2 \%)$ \\
II & $176(53.5 \%)$ \\
III & $68(20.7 \%)$ \\
IV & $28(8.5 \%)$ \\
Metastases & $60(18.2 \%)$ \\
Treatment & \\
Chemotherapy & $168(51.1 \%)$ \\
Hormonal treatment & $142(43.2 \%)$ \\
Mammography before diagnosis & \\
Never & $237(72.0 \%)$ \\
Not regularly & $46(14.0 \%)$ \\
Regularly (once every one or two years) & $46(14.0 \%)$ \\
Pap smear before diagnosis & \\
Never & $124(37.7 \%)$ \\
At least once & $140(42.5 \%)$ \\
Not regularly & $96(29.2 \%)$ \\
Regularly (once every one or two years) & $109(33.1 \%)$ \\
\hline
\end{tabular}

Univariate analyses revealed a number of parameters associated with a desire for detailed information about breast cancer (Table 3). Multiple regression analysis showed that age $(p<0.0005)$, educational level $(p<0.0005)$, employment status $(p=0.024)$, having a relative with cancer $(p=$ $0.016)$, frequency of mammography $(p=0.006)$ and having a pap smear at least once before breast cancer diagnosis $(p<0.0005)$ were the variables most highly predictive of the amount of information details desired (Table 3).

As shown in Table 4, the vast majority $(94.5 \%)$ preferred to know (absolutely need to know + I would like to know) whether their disease was cancer. However, $26.6 \%$ did not wish to be aware of the stage. Most women also wanted to know the exact treatment plan the physician had decided (95.1\%), the treatment options $(88.4 \%)$, and side effects $(93.3 \%)$. On the other hand, substantial minorities of patients did not wish to know the probability of disease recurrence $(40.4 \%)$ or the likelihood of cure $(23.4 \%)$.

\section{Decision-making preferences}

Two hundred and forty out of 329 preference orders $(73 \%)$ fell on the proposed underlying psychological dimension of keeping-sharing-giving away control (ABCDE- EDCBA), substantially above the 50\% plus one required to establish validity of the Control Preferences Scale [36]. The most frequently chosen preference order was EDCBA (the most passive one), preferred by 106 patients $(32.2 \%)$. The opposite end of the dimension (ABCDE) was chosen by only one participant, but this was sufficient to meet Coombs' criterion that a mirror image of the end scales must be present in the data set for the data for form a valid scale.

Results regarding patients' first preference are presented in Figure 1. The most frequently chosen alternative was E, the most passive of all roles, chosen by 149 women (45.3\%). Additionally, card D (passive collaboration) was chosen by 85 patients $(25.8 \%)$. Thus, the vast majority of patients $(71.1 \%)$ preferred to be in the passive end of the scale $(D+E)$, indicating that they did not want to be actively involved in making decisions about their treatment. On the contrary, card A, which stands for the most active role, was chosen by only one $(0.3 \%)$ and card B (active collaboration) by only 16 women $(4.6 \%)$, indicating that only a slight minority of subjects $(4.9 \%)$ preferred to be in the active end of the scale $(\mathrm{A}+\mathrm{B})$. Card $\mathrm{C}$, which stands for shared decision making, was chosen by 79 patients $(24.0 \%)$.

\section{Perceived choice of treatment and decision- making preferences}

One hundred eighty nine out of 229 women $(82.5 \%)$ who had stage I or II disease at the time of diagnosis felt they had no choice between mastectomy and breast conserving treatment. Those who preferred an active role were more likely to perceive that they actually had a choice in treatment decision making than those preferring collaborative or passive roles $(76.9 \%$ vs $23.1 \%$, respectively, $p<0.0005)$. Those who perceived 
Table 3. Factors associated with the amount of desired information details $(N=329)$

\begin{tabular}{|c|c|c|c|}
\hline \multirow[t]{2}{*}{ Variables } & \multirow[t]{2}{*}{ Univariate Analysis ( $p$-values) } & \multicolumn{2}{|c|}{ Multiple regression analysis } \\
\hline & & Standardized $\beta$ coefficients & $p$-Values \\
\hline \multicolumn{4}{|l|}{ Demographics } \\
\hline Age & $<0.0005^{\mathrm{a}}$ & -0.398 & $<0.0005$ \\
\hline Divorced/ widowed/ separated & $0.002^{b}$ & -0.015 & 0.747 \\
\hline Education & $<0.0005^{\mathrm{a}}$ & 0.292 & $<0.0005$ \\
\hline Employment status & $<0.0005^{b}$ & -0.121 & 0.024 \\
\hline Residence & $0.001^{b}$ & -0.025 & 0.600 \\
\hline Relative with cancer & $0.010^{b}$ & 0.105 & 0.016 \\
\hline Relative with breast cancer & $0.427^{b}$ & & \\
\hline \multicolumn{4}{|l|}{ Clinical parameters } \\
\hline Disease duration & $0.009^{c}$ & 0.018 & 0.689 \\
\hline Stage & $0.764^{d}$ & & \\
\hline Metastases & $0.236^{\mathrm{b}}$ & & \\
\hline Surgery & $0.158^{b}$ & & \\
\hline \multicolumn{4}{|l|}{ Screening procedures } \\
\hline Mammography before diagnosis (at least once) & $0.001^{b}$ & -0.132 & 0.339 \\
\hline Frequency of mammography before diagnosis & $<0.0005^{c}$ & 0.330 & 0.006 \\
\hline Pap test before diagnosis & $<0.0005^{b}$ & 0.235 & $<0.0005$ \\
\hline Pap test and mammography & $<0.0005^{\mathrm{a}}$ & -0.220 & 0.054 \\
\hline$R_{\AA \mathrm{dj}}^{2}$ & & 0.402 & \\
\hline Significance of $F$ change & & $F_{[11,317]}=21.07, p<0.0005$ & \\
\hline
\end{tabular}

apearson's correlation.

${ }^{\mathrm{b}}$ Two-tailed $t$-tests.

'Spearman's correlation.

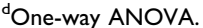

Table 4. Patient-specific information preferences $(N, \%)$

\begin{tabular}{|c|c|c|c|}
\hline Specific Information & $\begin{array}{l}\text { I absolutely } \\
\text { need to know }\end{array}$ & $\begin{array}{l}\text { I would } \\
\text { like to know }\end{array}$ & $\begin{array}{c}\text { I do not } \\
\text { want to know }\end{array}$ \\
\hline \multicolumn{4}{|l|}{ Disease } \\
\hline I. Whether or not this is cancer & $228(69.3 \%)$ & $83(25.2 \%)$ & $18(5.5 \%)$ \\
\hline 2. Which is the stage of the disease & $127(38.6 \%)$ & $113(34.3 \%)$ & $89(26.6 \%)$ \\
\hline 3. Which parts of the body are involved & $189(57.4 \%)$ & $104(31.6 \%)$ & $36(10.9 \%)$ \\
\hline 4. Possible effects of the disease to my body and my health & $165(50.2 \%)$ & $128(38.9 \%)$ & $36(10.9 \%)$ \\
\hline 5. What the probability of remission is & $87(26.4 \%)$ & $109(33.1 \%)$ & $133(40.4 \%)$ \\
\hline 6. Whether the disease is inherited or contagious & $|5|(45.9 \%)$ & $115(35.0 \%)$ & $63(11.1 \%)$ \\
\hline 7. Which are all investigative tests that she should do and when & $239(72.6 \%)$ & $77(23.4 \%)$ & $13(4.0 \%)$ \\
\hline \multicolumn{4}{|l|}{ Treatment } \\
\hline 8. What are all possible treatments & $152(46.2 \%)$ & $139(42.2 \%)$ & $38(11.6 \%)$ \\
\hline 9. What the exact treatment plan my doctor has decided is & $201(61.1 \%)$ & $112(34.0 \%)$ & $16(4.9 \%)$ \\
\hline 10. What the treatment will accomplish & $134(40.7 \%)$ & II 8 (35.9\%) & 77 (23.4\%) \\
\hline 11. What exactly the treatment will do inside my body & $79(24.0 \%)$ & $107(32.5 \%)$ & $143(43.5 \%)$ \\
\hline 12. What all possible side effects of treatment are & $185(56.2 \%)$ & $122(37.1 \%)$ & $22(6.7 \%)$ \\
\hline 13. What the likelihood of cure is & $143(43.5 \%)$ & $109(33.1 \%)$ & $77(23.4 \%)$ \\
\hline 14. How effective the treatment has been for other patients & $36(10.9 \%)$ & $125(38.0 \%)$ & $168(51.1 \%)$ \\
\hline 15. What is the best way to care for myself at home & $179(54.4 \%)$ & $133(40.4 \%)$ & $17(5.2 \%)$ \\
\hline \multicolumn{4}{|l|}{ Psychosocial } \\
\hline 16. Which is the best way to deal with my disease in a psychological level & $90(27.4 \%)$ & $140(42.6 \%)$ & $99(30.1 \%)$ \\
\hline 17. If there is a service where I could get psychological help & $76(23.1 \%)$ & $160(48.6 \%)$ & $93(28.3 \%)$ \\
\hline
\end{tabular}

having a choice were also more likely to have a strong desire for as many informational details as possible about breast cancer $(p=0.007)$.

\section{Factors associated with decision-making preferences}

Univariate analyses revealed a number of variables associated with decision-making preferences
(Table 5). Younger $(p<0.0005)$ and more educated women $(p<0.0005)$ were likely to prefer more active roles. On the contrary, being widowed or divorced $(p=0.007)$, living in a village $(p=0.001)$, being housewives or pensioners $(p<0.0005)$, and being treated with mastectomy $(p=0.007)$ were correlated with more passive roles. In addition, patients wishing to get a great amount of information details were likely to prefer more active 
involvement in treatment decision making $(p<0.0005)$. Screening procedures attended before diagnosis was positively correlated with decisionmaking preferences. Women who had at least once a mammography $(p=0.004)$ or a Pap test $(p<0.0005)$, or both $(p=0.001)$ were more likely to desire active roles. Frequency of mammography prediagnostically $(p=0.001)$ was also correlated to more active roles. Multiple regression analysis

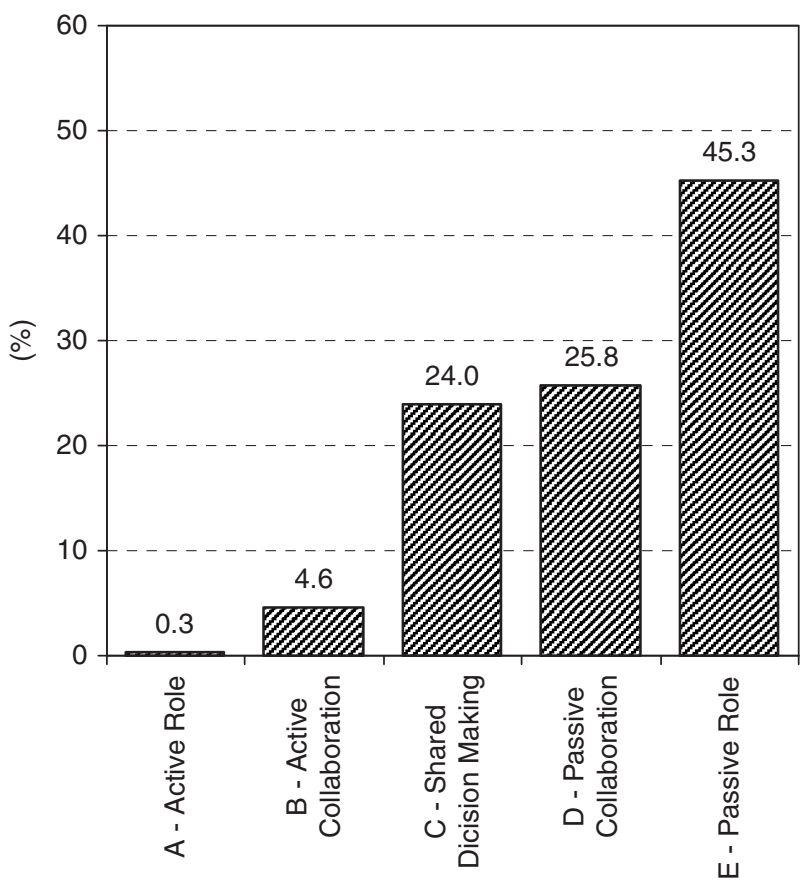

Figure I. Patient's decision-making preferences showed that age $(p<0.0005)$ and the amount of desired information details $(p=0.014)$ were the variables most highly predictive of decision-making preferences (Table 5).

\section{Discussion}

The results of this study showed that the vast majority of Greek women with breast cancer wanted to play a passive role in treatment decision making $(71.1 \%)$, with many wanting to delegate responsibility for the decision completely to their physician $(45.3 \%)$. A collaborative role was preferred by $24 \%$, whereas only $4.6 \%$ chose an active role. Moreover, although many women expressed a general desire for as much information about breast cancer as possible $(62.6 \%)$, a substantial proportion $(37.4 \%)$ did not want to get detailed information with half of them wishing to avoid awareness of bad news. Preference for a passive role was associated with less informational details desired, while both passive role choice and less information desired were associated with less frequently seeking screening services such as mammography and Pap test prediagnostically.

The proportion of patients who wanted to play a passive role in decision making in this study is the highest reported compared to similar studies from other countries [22-26,37-42]. In the Canadian study, the proportion of breast cancer patients who preferred a passive role was $34 \%$ [22], while a study in the United States reported rates as low as

Table 5. Factors associated with patients' decision making preferences $(N=329)$

\begin{tabular}{|c|c|c|c|}
\hline \multirow[t]{2}{*}{ Variables } & \multirow[t]{2}{*}{ Univariate analyses ( $p$-values) } & \multicolumn{2}{|c|}{ Multiple regression analysis } \\
\hline & & Standardized $\beta$ coefficients & p-Values \\
\hline \multicolumn{4}{|l|}{ Demographics } \\
\hline Age & $<0.0005^{\mathrm{a}}$ & -0.298 & $<0.0005$ \\
\hline Divorced/widowed/separated & $0.007^{\mathrm{b}}$ & -0.019 & 0.730 \\
\hline Education & $<0.0005^{\mathrm{a}}$ & 0.083 & 0.210 \\
\hline Employment status & $<0.0005^{\mathrm{b}}$ & 0.015 & 0.808 \\
\hline Residence & $0.001^{b}$ & 0.059 & 0.283 \\
\hline Relative with cancer & $0.440^{b}$ & & \\
\hline Relative with breast cancer & $0.518^{b}$ & & \\
\hline Amount of desired information details & $<0.0005$ & 0.160 & 0.014 \\
\hline \multicolumn{4}{|l|}{ Clinical parameters } \\
\hline Disease duration & $0.163^{\mathrm{a}}$ & & \\
\hline Stage & $0.882^{c}$ & & \\
\hline Metastases & $0.288^{b}$ & & \\
\hline Surgery & $0.007^{\mathrm{b}}$ & -0.003 & 0.946 \\
\hline \multicolumn{4}{|l|}{ Screening procedures } \\
\hline Mammography before diagnosis (at least once) & $0.004^{\mathrm{b}}$ & -0.192 & 0.253 \\
\hline Frequency of mammography before diagnosis & $0.001^{\mathrm{a}}$ & 0.233 & 0.100 \\
\hline Pap test before diagnosis & $<0.0005^{b}$ & 0.103 & 0.169 \\
\hline Pap test and mammography & $0.001^{\mathrm{b}}$ & -0.004 & 0.980 \\
\hline$R_{A \mathrm{dj} j}^{2}$ & & 0.275 & \\
\hline ANOVA & & $F_{[11,28]}=11.324, p<0.0005$ & \\
\hline
\end{tabular}

aSpearman's correlation.

bTwo-tailed t-tests.

'One-way ANOVA. 
$27 \%$ [37]. Although the relevant percentages reported in Europe are higher, with patients preferring a passive role being $24 \%$ in the Netherlands [38] and France [36], 47-54\% in Hungary [39], 52\% in United Kingdom [25], and 66\% in Sweden [24], the rates in Greece remain the highest ever reported. Moreover, in our study, $45.3 \%$ have chosen the most passive role, i.e. to leave all decisions to their doctor, compared to $3 \%$ in the United States [23], 10\% in Sweden [24], 12\% in France [36], 17.3\% in the United Kingdom [25], and $17.6 \%$ in Canada [22].

Many factors might contribute in the formation of a passive role among Greek women with breast cancer. First, Greek patients socialize in a cultural context where the paternalistic model of decision making dominates the view of the health-care consultations. Patients are assumed to play passive roles and may have learnt from previous interactions that a more active stance may not be well received by providers [5]. Thus, women may be afraid that if they play an active role, may be characterized as 'bad patients' [43], and consequently they will not receive good health-care services.

Second, perceived information or skill deficits at a time when quick decisions must be made may also discourage women facing a diagnosis of breast cancer to be actively involved in the consultation [5]. In addition, personal values and underlying personality characteristics may influence decisional preferences. Passive role choice might also reflect a tendency for seeking a trusting patient-doctor relationship that echoes that of the parent-child relationship, because of the emotional comfort it offers [43]. Finally, strong desire for passive roles in this study may reflect a cohort-effect, because our sample comprises patients who have received less education, compared to participants in other studies $[22,24,25,42]$.

Our results also showed that the proportion of patients who did not wish to be informed in detail about their disease is the highest reported compared to the results of studies in other countries, where the vast majority wanted to get as much information as possible about their illness [44-47]. For instance, 87 and $92 \%$ of cancer patients in two studies from the United Kingdom [45] and the United States [47] wanted as much information as possible about their disease, either good or bad, whereas in our study $37.4 \%$ wished to avoid awareness of bad news. This attitude toward information may also reflect the impact of the dominating paternalistic model of the doctor-patient relationship in the Greek medical encounter. Being afraid that disclosure of detailed information may lead cancer patients to disappointment, depression and despair, Greek physicians often avoid disclosing information about diagnosis, treatment options and prognosis. In two previous studies in
Greek cancer patients, 59\% were not aware of their diagnosis $[48,49]$. In accordance to this, in our study, $82.5 \%$ of women diagnosed with stage I or II disease did not understand that they had a choice between mastectomy and breast conserving surgery.

The patient's family often plays an important role in information disclosure in Greece. Patients' close relatives frequently demand the diagnosis of malignancy and illness information to be concealed from the affected individuals $[48,50]$. Hence, the avoidance of negative information might reflect patients' fear that active seeking of information will break the existing trust in the doctor-patient relationship or will agitate the relatives. Avoidance of bad news may also reflect denial, repression, or the patient's fear that awareness of 'bad news' will destroy him/her psychologically.

Of significant importance, in our opinion, is our finding that women who desired less informational details and preferred a passive role requested less frequently a mammography and/or Pap test prediagnostically. It should be noted that women in Greece are not invited to attend for screening mammography or Pap test and they have to actively request them; these screening tests are free for all through the social insurance system [29]. To the best of our knowledge, this is the first study reporting an association between screening procedures for cancer and decision-making preferences. Further research needs to be done to confirm this relationship, because of its considerable clinical implications, as it constitutes another reason for promoting shared decision making.

This study has some limitations, which need to be recognized. First, our sample comprised patients with a wide range of disease duration, ranging from recent diagnosis to many years, with a variety of stages of the disease. For many women, treatment would be a distant memory, while others (i.e. those with metastases) would presumably be involved in decisions about adjuvant therapy or palliative care. This might have provoked confusion to some patients about the notion of participation in decision making. Moreover, it has been reported that in women with breast cancer the greater the time since diagnosis the more passive the decisional role chosen [24]. Our results, however, showed that disease duration was not significantly associated with decision-making preferences, and this enabled us to proceed assessing the decision-making preferences in the entire sample, aiming at capturing general views about decision making. Another limitation is that the results about whether women with stage I or II breast cancer perceived that they had a choice between mastectomy and breast conserving treatment with radiation therapy were based on the patients' subjective experience. Interactions between health-care professionals and patients were not directly observed. Furthermore, 
our study was focused on the doctor-patient relationship and did not include patients' relatives, who often play a significant role in clinical consultation.

On the other hand, we selected a rather large sample of patients with reasonably high response rate $(90.4 \%)$ and we found no statistically significant differences between responders and nonresponders. Moreover, our hospital provides care to the majority of the breast cancer patients of the catchment area, suggesting that we recruited a representative sample of women with breast cancer.

In conclusion, our findings showed that the proportion of patients who wanted to play a passive role in decision making is the highest reported compared to similar studies from other countries, indicating the impact of the dominating paternalistic model of the doctor-patient relationship in the Greek medical encounter. However, active involvement and shared decision making have been shown to benefit some patients [19,51], while meeting the individuals' preferences had also positive effects on outcomes such as increased patient satisfaction, reduced decisional conflict, and improved compliance with treatment [52-54]. Therefore, health providers should make progress toward a more patient-centered care, providing the patients with the appropriate information and the choices available for their treatment, but always being sensitive in detecting signs of psychological distress or discontent.

\section{References}

1. Degner LF, Sloan JA. Decision making during serious illness: what role do patients really want to play? J Clin Epidemiol 1992;45:941-950.

2. Strull WM, Charles B. Do patients want to participate in medical decisions? J Am Med Assoc 1984;252(21): 2290-2294.

3. Emanuel EJ, Emanuel L. Four models of the physicianpatient relationship. J Am Med Assoc 1994;267(16): 2221-2226.

4. Deber RB. Physicians in health care management: 7. The patient-physician partnership: Changing roles and the desire for information. Can Med Assoc J 1994; 151(2):171-176.

5. Charles C, Gafni A, Whelan T. Shared decision making in the medical encounter: what does it mean? (Or it takes at least two to tango). Soc Sci Med 1997;44(5): 681-692.

6. Towle A, Godolphin W. Framework for teaching and learning informed shared decision making. $\mathrm{Br}$ Med $J$ 1999;319:766-771.

7. Sandman L, Munthe C. Shared decision making, paternalism and patient choice. Health Care Anal 2009; 18(1):60-84.

8. Butow PN, Maclean M, Dunn SM, Tattersall MHN, Boyer MJ. The dynamics of change: cancer patients' preferences for information, involvement and support. Ann Oncol 1997;8:857-863.

9. Kissane DW, Grabsch B, Love A, Clarke DM, Bloch S, Smith GC. Psychiatric disorder in women with early stage and advanced breast cancer: a comparative analysis. Aust N Z J Psych 2004;38(5):320-326.

10. Somerset W, Stout SC, Miller AH, Musselman D. Breast cancer and depression. Oncology (Williston Park) 2004;18(8):1021-1034.

11. Ganz PA. Psychological and social aspects of breast cancer. Oncology (Williston Park) 2008;22(6):642-646.

12. Hawley ST, Lantz P, Janz NK et al. Factors associated with patient involvement in surgical treatment decision making for breast cancer. Patient Educ Couns 2007;65:387-395.

13. Fisher B, Bauer M, Margolese R. Five year results of a randomized clinical trial comparing total mastectomy and segmental mastectomy with or without radiation in the treatment of breast cancer. $N$ Engl J Med 1985;312: 665-673.

14. Veronesi U, Cascinelli N, Mariani L et al. Twenty-year follow-up of a randomized study comparing breastconserving surgery with radical mastectomy for early breast cancer. N Engl J Med 2002;347(16):1227-1232.

15. Ashcroft JJ, Leinster SJ, Slade PD. Mastectomy vs breast conservation: psychological effects of patient choice of treatment. In Psychological Issues in Malignant Disease, Watson M, Greer S (eds). Pergamon Press: Oxford, 1986.

16. Morris J, Royle GT. Offering patients a choice of surgery for early breast cancer: a reduction in anxiety and depression in patients and their husbands. Soc Sci Med 1988;26:583-585.

17. Fallowfield LJ, Hall A, Maguire GP. Psychosocial outcomes of different treatment policies in women with early stage breast cancer outside a clinical trial. $\mathrm{Br} \mathrm{Med}$ $J$ 1990;301:575-580.

18. Fallowfield LJ, Hall A, Maguire P. Psychological effects of being offered choice of surgery for breast cancer. $\mathrm{Br}$ Med $J$ 1994;309:448.

19. Hack TF, Degner LF, Watson P, Sinha L. Do patients benefit from participating in medical decision making? Longitudinal follow-up of women with breast cancer. Psycho-Oncology 2006;15(1):9-19.

20. Wiggers JH, Donovan KO, Redman S et al. Cancer patient satisfaction with care. Cancer 1990;66:610-616.

21. Gattellari M, Butow PN, Tattersall MHN, Dunn SM, MacLeod CA. Misunderstanding in cancer patients: Why shoot the messenger? Ann Oncol 1999;10:39-46.

22. Degner LF, Kristjanson LJ, Bowman D et al. Information needs and decisional preferences in women with breast cancer. J Am Med Assoc 1997;277(18):1485-1492.

23. Keating NL, Guadagnoli E, Landrum MB, Borbas C, Weeks JC. Treatment decision making in early-stage breast cancer: should surgeons match patients' desired level of involvement? J Clin Oncol 2002;20(6):1473-1479.

24. Wallberg B, Michelson H, Nystedt M, Bolund C, Degner LF, Wilking N. Information needs and preferences for participation in treatment decisions among Swedish breast cancer patients. Acta Oncol 2000;39: 467-476.

25. Beaver K, Luker KA, Owens RG, Leinster SJ, Degner LF, Sloan JA. Treatment decision making in women newly diagnosed with breast cancer. Cancer Nurs 1995;18: $1-12$.

26. Bruera E, Willey JS, Palmer JL, Rosales M. Treatment decisions for breast carcinoma: patient preferences and physician perceptions. Cancer 2001;94(7):2076-2080.

27. Ferlay J, Parkin DM, Steliarova-Foucher E. Estimates of cancer incidence and mortality in Europe in 2008. Eur $J$ Cancer 2010;46:765-781.

28. Trigoni M, Griffiths F, Tsiftsis D, Koumantakis E, Green E, Lionis C. Mammography screening: views from women and primary care physicians in Crete. BMC Womens Health 2008;8:20. 
29. Souliotis K, Lionis C. Creating an integrated health care system in Greece: a primary care perspective. $\mathrm{J}$ Med Syst 2004;28:643-652.

30. Brotons C, Bjorkelund C, Bulc $\mathrm{M}$ et al. Prevention and health promotion in clinical practice: the views of general practitioners in Europe. Prev Med 2005;40: 595-601.

31. Degner LF, Sloan J, Venkatesh P. The control preferences scale. Can J Nurs Res 1997;29(3):21-43.

32. Cassileth BR, Zupkis RV, Sutton-Smith K, March V. Information and participation preferences among cancer patients. Ann Intern Med 1980;92:832-836.

33. Coombs CH. A Theory of Data. Wiley: New York, 1964.

34. Altman DG. Practical Statistics for Medical Research. Chapman \& Hall: London, 1991.

35. Miles J, Shevlin M. Applying Regression and Correlation. Sage: London, 2003; 165-191.

36. Protiere C, Viens P, Genre D et al. Patient participation in medical decision-making: a French study in adjuvant radio-chemotherapy for early breast cancer. Ann Oncol 2000;2:39-45.

37. Maly RC, Umezawa Y, Leake B, Silliman R. Determinants of participation in treatment decision-making by older breast cancer patients. Breast Cancer Res Treat 2004;85:201-209.

38. Jansen SJT, Otten W, Stiggelbout AM. Factors affecting patients' perceptions of choice regarding adjuvant chemotherapy for breast cancer. Breast Cancer Res Treat 2006;99:35-45.

39. Kahán Z, Varga K, Dudás R, Nyári T, Thurzó L. Collaborative/active participation per se does not decrease anxiety in breast cancer. Pathol Oncol Res 2006;12(2):93-101.

40. Bilodeau BA, Degner LF. Information needs, sources of information and decisional roles in women with breast cancer. Oncol Nurs Forum 1996;23:691-696.

41. Lam W, Fielding R, Chan M, Chow L, Ho E. Participation and satisfaction with surgical treatment decision-making in breast cancer among Chinese women. Breast Cancer Res Treat 2003;80:171-180.

42. Sabo B, St-Jacques N, Rayson D. The decision-making experience among women diagnosed with stage I and II breast cancer. Breast Cancer Res Treat 2007;102:51-59.
43. Lupton D. Medicine as Culture. Illness, Disease and the Body in Western Societies. Sage: London, 2003.

44. Sutherland HJ, Llewellyn-Thomas HA, Lockwood GA, Tritchler DL. Cancer patients: their desire for information and participation in treatment decisions. $J R S o c$ Med 1989;82:260-263.

45. Jenkins V, Fallowfield L, Saul J. Information needs of patients with cancer: results from a large study in UK cancer centres. Br J Cancer 2001;84:48-51.

46. Fallowfield L, Ford S, Lewis S. No news is not good news: information preferences of patients with cancer. Psycho-Oncology 1995;4:197-202.

47. Blanchard CG, Labreque MS, Ruckdeschel JC et al. Information and decision making preferences of hospitalized adult cancer patients. Soc Sci Med 1988;27(11): 1139-1145.

48. Brokalaki EI, Sotiropoulos GC, Tsaras K, Brokalaki H. Awareness of diagnosis, and information-seeking behavior of hospitalized cancer patients in Greece. Supp Care Cancer 2005;13(11):938-942.

49. Iconomou G, Vagenakis GA, Kalofonos PH. The informational needs, satisfaction with communication, and psychological status of primary caregivers of cancer patients receiving chemotherapy. Supp Care Cancer 2001;9:591-596

50. Mystakidou K, Tsilika E, Parpa E, Katsouda E, Vlahos L. Patterns and barriers in information disclosure between health care professionals and relatives with cancer patients in Greek society. Eur J Cancer Care 2005;14: $175-181$

51. Gattellari M, Butow PN, Tattersall MHN. Sharing decisions in cancer care. Soc Sci Med 2001;52: 1865-1878.

52. Shepherd HL, Tattersall MHN, Butow PN. The context influences doctors' support of shared decision making in cancer care. Br J Cancer 2007;97:6-13.

53. Anderson R, Funnell M, Butler P, Arnold M, Fitzgerald J, Feste C. Patient empowerment: results of a randomized controlled trial. Diabetes Care 1995;18:943-949.

54. Jahng KH, Martin LR, Golin CE, DiMatteo MR. Preferences for medical collaboration: patient-physician congruence and patient outcomes. Patient Educ Couns 2005;57:308-314. 